\title{
Exploring negative territory Carbon dioxide removal and climate policy initiatives
}

\author{
James Meadowcroft
}

Received: 21 May 2012 /Accepted: 23 December 2012 / Published online: 18 January 2013

(C) The Author(s) 2013. This article is published with open access at Springerlink.com

Over the last five years there has been increased scientific interest in the role carbon dioxide removal (CDR), or 'negative carbon dioxide emissions', might play in addressing anthropogenic climate change. CDR is typically understood to include approaches such as large scale afforestation and reforestation, biomass energy based carbon capture and storage, direct air capture, ocean fertilization, and enhanced weathering. Each of these could remove emissions from the atmosphere, slowing (or perhaps ultimately reversing) the accumulation of carbon dioxide contributing to an enhanced greenhouse effect. Along with solar radiation management (SRM), CDR has been presented as a prospective avenue for 'geoengineering'-the deliberate attempt to modify the global environment, in this case to counteract harm associated with human induced climate change (Royal Society 2009).

This article engages with these issues, considering the significance of CDR approaches for climate policy. It is organized in three sections: the first provides a brief introduction to CDR; the second explores its possible place in long term climate policy; the third considers nearer term policy issues.

\section{Approaches to CDR}

While there are now rapidly developing technical literatures on CDR approaches (for example, Azar et al. 2010; Lackner 2009; Lenton and Vaughan 2009; Ranjan and Herzog 2011) the following brief descriptions are adequate to ground the discussion here.

Afforestation and reforestation remove $\mathrm{CO}_{2}$ from the atmosphere, and result in a net accumulation of carbon in living biomass. However, if the forest is subsequently destroyed the carbon will be released, so this option depends on addressing issues of long term forest management. For large scale applications there is a potential tension with competing land uses (for example, food production, commercial forestry, bio-energy crops, settlements). Costs are assumed to be initially relatively low, at least until land use dilemmas become more acute.

This article is part of a Special Issue on "Carbon Dioxide Removal from the Atmosphere: Complementary Insights from Science and Modeling" edited by Massimo Tavoni, Robert Socolow, and Carlo Carraro.

J. Meadowcroft $(\bowtie)$

School of Public Policy and Administration, Carleton University, Ottawa, Ontario, Canada

e-mail: jmeadowc@connect.carleton.ca 
Bioenergy carbon capture and storage (BECCS) applies CCS to biomass feed-stocks, for example in electricity generation or the production of liquid biofuels. Since the biomass fuel cycle is assumed to be approximately carbon neutral (the next crop will absorb the $\mathrm{CO}_{2}$ emissions released by exploiting this year's harvest), sequestering $\mathrm{CO}_{2}$ emissions results in net atmospheric removal. BECCS is likely to be somewhat more costly than fossil fuel based CCS because of scale issues (more expensive biomass feedstock and smaller facilities). BECCS potential is related to the place of biomass/biofuels in the energy system. The greater the societal reliance on bio-energy, the greater the volume of $\mathrm{CO}_{2}$ emissions that could be sequestered by this route. BECCS also requires suitable geological storage sites.

Near-surface sequestration stores carbon from material of biological origin in soils or the near sub-surface. One alternative is biochar (charcoal) which can be mixed into soil, trapping substantial amounts of carbon with potential benefits for agricultural productivity. Another option would be to bury biomass in conditions that would prevent normal decay. While energy could be recovered from creating biochar, large scale burial of biomass would provide no direct co-benefits.

Direct Air capture (DAC) involves the direct draw down of $\mathrm{CO}_{2}$ from the atmosphere and its subsequent sequestration, typically in a geological formation. Air capture facilities could be sited near suitable storage sites so removing the transport requirement of industrial-based CCS. The difficulty is that atmospheric concentrations of $\mathrm{CO}_{2}$ are much lower than those found in combustion flue gases. Air capture remains at a relatively early stage of development. As with conventional CCS and BECCS, it requires suitable storage sites.

Ocean fertilization relies on mineral seeding of the ocean to encourage the uptake of carbon dioxide by biological organisms which will eventually die and transport $\mathrm{CO}_{2}$ into the deep ocean. Iron fertilization appears the current favorite although other candidates have been proposed including nitrogen and phosphorous. Important uncertainties remain about the effectiveness of the process and about potential side effects including the impact on ocean ecology.

Enhanced weathering would exploit natural chemical processes whereby exposed minerals are slowly transformed by the absorption of $\mathrm{CO}_{2}$. A variety of chemical pathways could be used, but most would involve mining and crushing rock to accelerate $\mathrm{CO}_{2}$ uptake, with deposition to land or ocean.

For the purposes of this discussion we do not deal with $\mathrm{CO}_{2}$ removal that is part of a closed loop fuel cycle - for example air capture coupled with gasoline production (green gasoline) or stand alone biofuels - because the captured $\mathrm{CO}_{2}$ is released with combustion, and there is no net withdrawal. Nor do we consider approaches that use industrial $\mathrm{CO}_{2}$ sources such as reacting limestone and power-plant $\mathrm{CO}_{2}$ in sea water and releasing the resultant calcium bicarbonate to the ocean-even if they are similar to CDR pathwaysbecause there is no net atmospheric draw down.

On the basis of the short descriptions given above, several initial observations can be made. First, CDR approaches vary widely. As a group they share a capacity to remove $\mathrm{CO}_{2}$ from the atmosphere, but not a lot more. The $\mathrm{CO}_{2}$ is captured and stored by varied mechanisms, involving different natural processes and forms of human activity. The approaches present varied profiles of costs and benefits, potential side effects and risks, and limiting factors (Bipartisan Policy Center 2011). Preliminary efforts have been made to systematize some of these issues. For example, the Royal Society's report on geoengineering scored CDR approaches with respect to cost, maximum potential $\mathrm{CO}_{2}$ reduction (in $\mathrm{ppm}$ ) over this century, ultimate constraints, significance of anticipated environmental effects, and risk of unanticipated environmental effects (2009). 
One important difference relates to the destination of the stored carbon. For afforestation and reforestation this is the terrestrial biosphere. For near-surface sequestration it is soil or the shallow underground. BECCS and air capture are today primarily considered in relation to geologic storage (although in principle the $\mathrm{CO}_{2}$ could be deposited in the oceans). With ocean fertilization the destination is by definition the ocean. For enhanced weathering it could go either for surface or ocean deposition. Each storage option has advantages and disadvantages. Carbon sequestered in forests, for example, remains highly vulnerable to natural or human disturbance. Direct intervention in ocean ecosystems stands out as particularly problematic. The ocean constitutes an open ecosystem, and changes potentially affect all ocean waters and the life they contain. Moreover, scientific knowledge of the oceans lags significantly behind our understanding of the terrestrial ecosphere. Of course, atmosphere and oceans are in long term equilibrium, so a large fraction of the $\mathrm{CO}_{2}$ emitted by humans to air ultimately finds its way into the ocean.

From a policy perspective another important distinction is that, unlike other CDR approaches, afforestation and reforestation are already practical options that can be carried out at reasonable cost and are recognized under existing international climate agreements. Long before they were re-conceptualized as forms of 'CDR' they had been integrated (as land use changes) into national GHG inventory reporting under the UNFCCC, and recognized as carbon offset strategies under the Clean Development Mechanism (CDM) of the Kyoto Protocol. Measures to support developing countries reduce emissions from deforestation and forest degradation (REDD) are a focus of continuing international negotiation, with current estimates of gross carbon releases from the destruction of tropical forests ranging from about $0.8 \mathrm{PgC}$ per year to 2.8 PgC per year (Pan et al. 2011; Harris et al. 2012; Baccini et al. 2012).

The diversity of potential CDR approaches can be understood as an advantage: it provides a number of avenues that might prove fruitful. But it also suggests that it makes only limited sense to talk about CDR in the abstract. The key lies in the specific approach (with its particular operative mechanisms, limits, risks, and costs), and in determining the particular conditions under which it could be deployed in a socially beneficial manner.

Second, scale obviously matters. In the first instance scale relates to the quantity of carbon that could ultimately be drawn down, the rate at which this might be accomplished and the span of time it would remain isolated from the atmosphere. Estimates of these magnitudes are sensitive to initial assumptions (availability of the pathway, limiting factors, costs and so on). One recent study of terrestrial biological CDR, for example, suggested by 2050 an afforestation/reforestation potential of $1.5 \mathrm{PgC}$ year (with an ultimate potential of $300 \mathrm{PgC}$ ); a biochar potential of up to $0.87 \mathrm{PgC}$ year (with an ultimate potential of $500 \mathrm{PgC}$ ); and a BECCS potential of up to $4 \mathrm{PgC}$ year (limited ultimately by the availability of geological storage at 500-3000 $\mathrm{PgC}$ ) (Lenton 2010). These are very large annual flows that would make a noticeable impact on the approximately $8 \mathrm{PgC}$ currently released each year by fossil fuel combustion. Similarly large numbers have been discussed for other CDR approaches such as direct air capture at a rate of 1 $\mathrm{PgC}$ per year after fifty years of effort (Socolow et al. 2011), or enhanced weathering (Kohler et al. 2010). But in each case the reductions would require an immense societal effort: planting and managing millions of square kilometers of forest; processing biological materials to generate energy and capture emissions and/or incorporate carbon into soils; deploying direct air capture and injecting $\mathrm{CO}_{2}$ underground; or extracting and processing minerals at 'the same order of magnitude' as 'the energy system that produces $\mathrm{CO}_{2}$ ' (Royal Society 2009, 13). So, scale must also be thought about in terms of the human activity required to realize the approach, the scope of existing societal practices that must be transformed, the land-use footprint and potential environmental impacts. And this suggests ambitious estimates of CDR potentials - especially by mid-century - must be viewed with caution. 
Third, all these approaches confront uncertainties on multiple dimensions. Although human societies have long practical experience with forestry and forest management we are still learning about forest ecosystems, and knowledge spanning the centuries-long life cycle of forest biomes is limited. Research on biochar is in its infancy (even if practices using biochar for soil enhancement go back millennia). There is no research on burying biomass. Knowledge of ocean ecosystems is limited and ocean/atmospheric linkages are only partly understood. Even knowledge of the subsurface is partial —with quite a bit understood about the geology of fossil fuel bearing formations, but much less about the rest, including the connections between biological processes at depth and the surface biosphere (Lovley and Chapelle 1995).

\section{CDR and long term climate management}

To explore the policy significance of CDR it is helpful initially to distinguish two ways of understanding its potential contribution:

- CDR as an emission offset strategy: On this vision CDR approaches are considered as an emission reduction option: the focus is on offsetting ${ }^{1}$ current emissions to slow atmospheric accumulation of greenhouse gasses and to avoid overshoot of a desired atmospheric stabilization target for $\mathrm{CO}_{2}$. Thus $\mathrm{CDR}$ approaches join the vast array of other mitigation options, and they can be compared with these alternatives when designing an appropriate portfolio of climate responses. However, since CDR options (with the exception of afforestation and reforestation) are expensive, they would be unlikely to be deployed at significant scale in the near term.

- CDR as a climate recovery strategy: On this vision CDR could play a critical role in the societal response to a serious emissions overshoot. If societies prove unable to bring down greenhouse gas releases in a timely manner, and the resultant atmospheric $\mathrm{CO}_{2}$ concentrations are judged to be too high, CDR provides an avenue to roll back the accumulation to more comfortable levels (Keith et al. 2006). Here CDR appears as a basket of restorative technologies that can gradually undo the change in the composition of the atmosphere that has been driven by fossil fuel combustion since 1800. Such an effort could require large scale deployment of several CDR approaches, over many generations.

The two patterns of deployment are logically distinct, and can be considered as alternatives or as complements. It would be possible (a) to employ CDR as an offset strategy, but then accept to live with the atmospheric $\mathrm{CO}_{2}$ levels that resulted from the historic emissions trajectory. Alternatively (b), large scale CDR deployment might take place (as a climate recovery strategy) only after the ongoing emissions problem had been cracked by conventional mitigation approaches. Or (c) the second pattern could flow from the first, with CDR employed initially to aid emissions control (offset) and then subsequently to secure net negative global emissions (recovery).

\footnotetext{
${ }^{1}$ 'Offset' is used here in the generic sense of 'cancelling', 'balancing', or 'neutralizing' (The New Shorter Oxford English Dictionary 1993). Thus CDR can be understood to counteract $\mathrm{CO}_{2}$ emissions just as positive and negative entries cancel out in financial accounts. There is a more specific technical understanding of 'carbon offset' where reductions are secured outside the formal boundaries of a regulatory regime. Such reductions may be recognized as providing credits within that system (for example, CDM offsets in the EU ETS), or not (as in the case of the voluntary carbon offset market).
} 
Considered as an emissions offset strategy CDR offers several potential advantages. First, it could be applied to 'buy time' for the development of technological alternatives and the adjustment of societal practices. For a given a stabilization target, successful CDR would enable emissions to continue longer, either because some sources were counterbalanced by contemporaneous CDR, or because immediate emissions reductions could be delayed since larger reductions could be secured in the future when CDR was added to the mitigation portfolio. Second, CDR could reduce the costs of meeting a given abatement target. Although CDR will be expensive, at some point cheaper mitigation options will be exhausted and CDR could help contain the overall cost of the abatement effort. Third, CDR could make feasible a more aggressive emissions reduction effort. By driving net emissions down more quickly atmospheric accumulation could peak at a lower level and over a given time period lower stabilization levels could be achieved. Forth, CDR could enable fossil fuels to remain a significant part of the energy mix for a longer period. Fossil fuels have powered industrial growth for several centuries and moving away from such an energy trajectory is a major challenge. The direct application of CCS to large fossil fuel facilities (power plants, refineries, and so on) would dramatically reduce emissions from these sources. But CDR could provide additional 'head room' for continued fossil fuel emissions. This could be understood in relation to dispersed or mobile sources where CCS is not practical, or to that fraction of the life-cycle emissions from large point sources which CCS could not trap except at prohibitive cost.

Each of these potential advantages would be accompanied by costs and risks. To 'buy time' suggests time will be spent in developing alternatives and preparing a greater emissions reduction effort in the future. But it might simply be an excuse for deferring inconvenient societal adjustment. Reduced costs or the possibility of attaining a lower initial stabilization target sound great, but one must be confident that side effects and unintended consequences will not cause commensurate difficulties. While extending the use of fossil fuels has advantages, it also has disadvantages. Fossil fuels are associated with a wide range of health and environmental impacts. Continuing reliance on fossil fuels, involving a further investment in infrastructure (including that required for CCS), is likely to intensify technological and social 'lock in' (Unruh 2000; Vergragt et al. 2011), and slow the transfer of investment towards alternative energy technologies. It is also important to note that some of the potential CDR advantages are mutually contradictory: one cannot use CDR to 'buy time', and simultaneously use it to pursue a more aggressive climate stabilization target.

Considered as a climate recovery strategy $\mathrm{CDR}$ has one central advantage: drawing $\mathrm{CO}_{2}$ down from the atmosphere can reduce the risks attendant upon maintaining concentrations substantially above pre-industrial levels for a protracted period of time.

Return from an overshoot trajectory is far from the ideal response to the risks posed by anthropogenic climate change. In the first place, CDR could not reverse the damage incurred during the period where $\mathrm{CO}_{2}$ concentrations are artificially elevated. Second, CDR does not offer a quick fix: with a heroic effort it might achieve reductions of perhaps $1-2$ ppm a year, so it would be a long haul if atmospheric concentrations of $\mathrm{CO}_{2}$ were to be brought down to close to pre-industrial levels. Third, there is an unquantifiable risk of exposure to climate 'tipping points' which, once crossed, might shift elements of the climate system into a configuration that was not readily reversible (Schellnhuber 2006). Presumably, the further the climate moves into overshoot territory, and the longer the time spent there, the more serious these risks become.

Whether or not CDR was deployed earlier as an offset strategy, its use as a recovery strategy would raise the issue of how far back to roll $\mathrm{CO}_{2}$ concentrations, the pace at which 
this should be accomplished, and the scale of the associated effort. It seems likely that this would prove contentious. Uncertainties about the risks of maintaining high $\mathrm{CO}_{2}$ levels are likely to remain for some time. A large scale CDR effort requires resources and is not without risks. Impacts of a changing climate will be unevenly distributed, and some regions or groups are likely to gain from a warmer world. Perhaps most importantly, adaptation (migration, changing crops, rebuilding infrastructure) can be effected on a more rapid timescale than the one on which CDR operates. And to the extent that some societies have come to terms with the new climate, will they be so eager to see it disappear? In any case, it is hard to imagine remedial CDR operating outside the context of international agreement (Virgoe 2009; Horton 2011). After all, international emissions controls would almost certainly be required to secure atmospheric stabilization, and CDR could easily be undone by renewed fossil fuel combustion.

Finally, it is worth noting that to the extent that overall CDR potential is limited (by land use competition, shortage of available geological storage sites, growth of side effects of sequestration activities, and so on), the more that CDR is used as an offset strategy the less the CDR potential that would remain available for subsequent climate recovery (and the higher its eventual cost).

The upshot of this discussion is that as a climate recovery strategy CDR is not of great practical relevance to climate change policy today. Of course, additional research that establishes more clearly the ultimate potential — but also the risks - of distinct CDR approaches is useful. But at the moment we are having difficulty achieving even modest (and relatively inexpensive) emissions cuts in the developed countries, to say nothing of capping global GHG emissions or stabilizing atmospheric concentrations. Deployment of $\mathrm{CDR}$ as a climate recovery strategy lies beyond the planning horizons of public and private sector organizations, and almost certainly beyond the lifetimes of current decision-makers. The one substantive choice that could be made in the short term in relation to CDR as a recovery strategy would be to defer GHG mitigation efforts today because large scale CDR might be possible in the future. In light of current projections of where 'business as usual' will take us over the course of this century, the substantial risks associated with warming above a few degrees, and the long time frames over which CDR would need to operate, it would seem imprudent to make such a case. So we must simply acknowledge that future generations will make the choices over CDR as a recovery strategy - although of course, by our current action or inaction on climate policy, we can influence the environment in which they will ultimately make these choices.

\section{CDR and current policy concerns}

Where CDR approaches do enter current policy space is as potential offsets to ongoing emissions over coming decades. Here the first issue is to distinguish among CDR pathways. As we have seen, CDR is not a single approach or technology. So what is needed is not a 'policy perspective on CDR', but rather a suite of perspectives appropriate to the variety of techniques and contexts. Such a differentiated policy stance is important because CDR approaches have different fundamental characteristics as well as distinct implications for established human practices relating to agriculture, energy systems, land use, biodiversity protection, and so on (see Table 1). Moreover, societal actors can be expected to respond to these approaches (embracing or condemning them) on the basis of specific development proposals - for example, to build new infrastructure, to change land use, to geologically sequester $\mathrm{CO}_{2}$ nearby, to initiate afforestation, and so on - and not as manifestations of some 


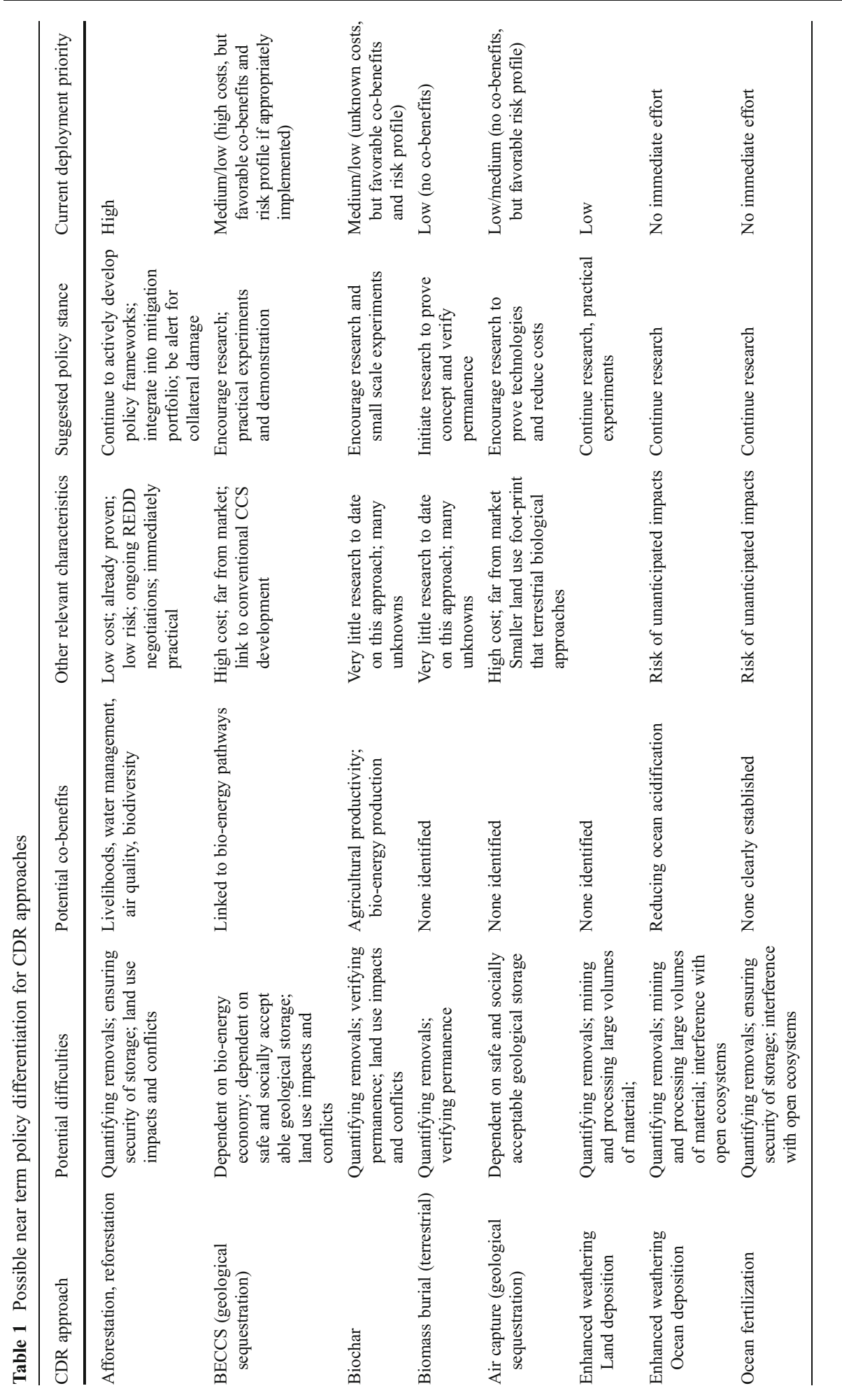


abstract process of CDR. Thus the policy and regulatory frameworks governing CRD activities must be tailored to each particular approach. Moreover, policy differentiation is not just about selecting preferred techniques, but above all about ensuring that techniques that are deployed are implemented appropriately. For example, some studies suggest that poorly implemented BEECS strategies could actually increase GHG emissions through indirect land use changes (for example, energy crops displacing food production and encouraging additional forest clearances) (Creutzig et al. 2012).

One could imagine governments directly financing activities to draw down $\mathrm{CO}_{2}$ as a public good, but the thrust of climate policy to this point has been to make emitting entities responsible for abatement, and to enlist the price mechanism (through a carbon tax or cap and trade system) to encourage adaptation across the economy. On this model, CDR activities would result in carbon dioxide reduction credits. Whichever CDR approaches are favored, their integration into mitigation frameworks requires mechanisms to: a) establish atmospheric withdrawals are actually taking place at the intended levels, b) ensure the long term security of the sequestered carbon, and c) minimize collateral damage.

Quantitative verification of $\mathrm{CO}_{2}$ flows is required for national greenhouse gas inventories and compliance with international accords; but it is also critical for businesses. While reasonably accurate estimates of emissions and emissions reductions can be made from data on fossil fuel consumption, things are more complex with removals. Consider forests: actual $\mathrm{CO}_{2}$ uptake varies according to forest types, species mix, maturity, and climactic conditions. Carbon uptake will be spread over decades and historic data on forest growth may prove misleading, especially as the climate changes. While quantifying $\mathrm{CO}_{2}$ sent for geological storage from BECCS or air capture may be reasonably straightforward, the same is far from true for biochar, enhanced weathering or ocean fertilization. This implies strict protocols for the operation of CDR projects, and appropriate measurement and verification regimes.

For CDR to be effective, sequestration must be for the long term. What happens if a newly planted forest is eroded by agriculture, settlement, fire, or insect attack; if geologic storage for air capture or BECCS proves insecure; or fraud exaggerates long term sequestration figures? In many cases measurement and monitoring will have to continue for the long term. It also implies the preparation of appropriate remediation and compensation plans (if storage breaks down) and associated liability regimes.

With respect to collateral damage, the standard assumption is that CDR would be pursued because it could be secured at favorable cost as compared to emissions abatement options. But this is only to the overall benefit of society if the full social cost (as opposed to the cost for the specific actors realizing a project) is lower for the CDR pathway. This means other 'externalities' accompanying CDR projects must be taken into consideration. Ultimately, the only way to deal with these is by the regulation of authorized technologies/approaches by public authorities: on the one hand, through international rules relating to each CRD class (with project compliance a pre-condition for international recognition of carbon removal credits); and on the other, through national and local rules relating to land use planning, environmental and safety issues, and so on. But the difficulty which policy systems have in managing issues of such complexity, with multiple cross-cutting interconnections and uncertainties, cannot be overstated (Meadowcroft 2007). A recurrent theme in the political science literature is the incremental, contingent and fragmented character of policy making in modern democracies; and the difficulty in pursuing 'rational-comprehensive' approaches to problem solving (Lindblom 1979; Kingdon 1984).

It is impossible to anticipate in advance all the consequences from hypothetical CDR projects. Only with time will some impacts be appreciated, and will the benefits and costs of each CDR option be fully understood. Appropriate policy frameworks must therefore 
include opportunities for regular review, and iterative policy learning (Bennet and Howlett 1992). Above all, this suggests that it is prudent to introduce these approaches gradually and at a modest scale that allows careful assessment of difficulties, adjustment to regulatory frameworks, and time for societal debate about the implications of different choices to mature.

Presently, a certain 'unreality' continues to cloud discussion of CDR. This is related to the relative immaturity of many of the proposed techniques as well as to the continuing impasse in the international climate negotiations. The recent framing of CDR, which coupled it to SRM as a core technique for 'geoengineering', has not been entirely helpful. The approaches share one essential feature: they could be deployed to address climate risks, even if significant abatement of emissions from fossil fuel combustion is postponed. So, in a context where many in the climate science community were frustrated with the inability of political leaders to effect serious GHG emission reductions, despite several decades of international talks and increasing evidence of the climate threat, it seemed to make sense to contemplate a 'Plan B'- to explore a menu of technical options for large scale management of the climate system should humanity fail to abandon promptly its emission-dependent development trajectory. Yet the same political impasse that prompted the call for an expanded research agenda on 'geoengineering' made the scope of its ambition and associated techniques appear far removed from immediate concerns. Moreover, there are important differences among the technologies listed under these umbrella headings ${ }^{2}$ : and while it has been argued that SRM options could be deployed at low cost to relatively quickly attenuate a temperature rise, CDR approaches operate comparatively slowly and (generally) at significant cost. Conceptually, CDR can be understood as a pollution clean-up approach (drawing down offending emissions), while SRM intervenes at another point in the climate system to reduce harm (reflecting incident solar radiation to reduce warming). The concern is that such upstream intervention: (a) may generate broader system impacts (for example, negative regional effects) and b) fail to deal with all salient features of the original disturbance (for example, ocean acidification). Of course, pollution clean-up can also generate harm and some of the potential concerns with specific CDR pathways have been discussed above.

In the absence of real world experience with most CDR technologies, their potential is being probed by models that remain at a fairly high level of abstraction and which suggest these approaches may be rolled out as the carbon price rises over the course of the century. Although this modeling is already generating important insights (see the contributions in this issue), it is important not to lose sight of its limitations. The time frame over which developments are being explored is one concern: while an extended horizon makes sense from the perspective of the overall character of the climate problem, it goes far beyond our capacity realistically to anticipate societal development. In looking forward a century we face challenges similar to those that would have confronted researchers trying to foresee the present world from a vantage point in 1913. Over such a span geopolitical realities, technological capacities, societal practices and cultural mores can shift dramatically. Even a forty year horizon is ambitious. Think how just one change - the advent of shale gas over the last five years - has dramatically altered the energy picture in North America and beyond (IEA 2012).

Moreover, when we contemplate a particular modeled mix of mitigation optionsgenerated by interactions among a high carbon price, and the relative cost of diverse emission abatement/carbon removal technologies - it is worth remembering that our ability

\footnotetext{
${ }^{2}$ For a good discussion of the conceptual ambiguity of 'geoengineering' and the diversity of technologies/approaches with which it can be linked see Keith, 2000.
} 
to anticipate technology learning curves and societal attitudes towards the deployment of particular technologies is severely constrained (Torvanger and Meadowcroft 2011). The relative cost profiles which will confront future societies will be determined not just by inherent properties of these technologies but also by their actual historical development, which will be influenced by public and private investment decisions, policy choices and regulatory frameworks, operational experiences (reliability, accidents, etc.), and public attitudes and political struggles. In an area as politically charged as energy policy, where governments intervene continuously to alter the landscape within which technological development occurs (through R\&D expenditure, deployment subsidies, tax policy, environmental and land use policies), it is not just the carbon price that is 'politically constructed', but to a certain extent the relative prices of all energy and climate technologies. So it is not clear what we can infer today about relative costs of mitigation options confronting decision makers fifty or more years from now.

In any case, with respect to actual choices over technology deployment, comparative cost is not the only factor which governments (or even private actors) take into consideration. In deciding to turn their back on nuclear power German governments have not been driven principally by a subtle calculus of relative costs, but by persistent public opposition which is deeply rooted in national political culture. In real world energy policy governments routinely rule out options that may have a cost advantage to pursue other ends, and often expend public resources to protect the economic position of powerful producer groups. In the most straightforward sense this matters for CDR because government action at many levels (local, regional, national, and international) and in many forms (R\&D support, establishing regulatory frameworks, permitting of facilities, authorizing land use changes, establishment of liability regimes, and so on) is necessary if these technologies are ever to be introduced at scale.

There is now a substantial literature (Dosi 1982; Freeman 1996; Sanden 2004) on long term socio-technical transitions that emphasizes (Geels 2005; Geels and Schot 2007): the long lead times required for basic discoveries to achieve their full societal potential; the contrast between normal process of incremental change within a dominant technological paradigm and more radical innovations that lead to regime change; the critical importance of societal practices (finance, training, maintenance, industry standards, regulation and property rights, investor and consumer expectations, and so on) in 'locking in' 'dominant designs'; and the significance of interactions among 'niche', 'regime' and 'landscape' factors in facilitating transformation (Smith et al. 2010). This is of relevance not just to the future technical development of CDR, but to the evolution of all the other mitigation options against which it will eventually compete. It suggests that despite the enormous capacity of established interests to achieve incremental efficiency gains with existing technologies and to deploy political lobbying to frustrate change, over time alternatives can acquire increasing traction. In particular, the potential for non carbon-based energy technologies to achieve major advances, that would alter their appeal (in terms both of functionality and cost) in relation to fossil energy systems and eventual CRD mitigation approaches, should not be ignored.

There is another way in which current consideration of CRD remains abstract: to date we have a limited appreciation of the range of societal impacts that will be associated with CDR deployment at scale. Typically it is only as a technology is rolled out into society that one can get a firm grip on the timing and strength of side effects, the operation of countervailing forces, and the mobilization of direct opposition. Biofuels and wind provide recent examples. For several decades technical arguments about first generation biofuels continued in the scientific literature, but only when biofuels emerged into international markets did impacts 
become concrete, and critiques dealing with land tenure, water use, food prices, and so on, gained wider purchase. Similarly, in many countries wind deployment increasingly has been met with organized opposition. In both cases land use conflicts have been central; and we can anticipate that this will ultimately present serious challenges to bio-based terrestrial CDR. Similarly, the issue of underground storage may be a problem for BECCS and DAC, for pilot CCS projects have already encountered public opposition (for example, in the Netherlands and Germany). Although such objections ultimately may be overridden, it is clear that over time different sorts of environmental, social and economic consequences of CDR deployment will become more concrete and will inspire societal responses. Above all, it is important to remember that while these reactions may be articulated by particular groups and interests, they reflect real perceptions about societal impacts and underlying conflicts over the distribution of social resources.

The decision to deploy a particular CDR approach to cancel ongoing emissions will always be about relative costs and benefits. Every mitigation option has advantages and disadvantages, and only by comparing these can reasonable abatement strategies be designed. In making energy and climate mitigation related choices, governments weigh many considerations including energy security, economic prosperity, regional development, non-GHG environmental effects, and so on. In this sense, it is appropriate to assess CDR approaches not just from the perspective of their mitigation potential (tons removed over time), but also by asking what sort of societal development trajectory they imply. A civilization that employed large scale afforestation and reforestation, for example, would look very different from one that declined this option; widespread BECCS implies an extensive bio-energy economy, and so on. Choices about CDR approaches, and the scale at which they are to be deployed, cannot be isolated from broader decisions relating to societal practices driving emissions growth. Lower levels of population growth or material consumption (for example, the proportion of meat in diets) would moderate land use conflicts, so facilitating some CDR approaches. On other hand, easing of these drivers might make large scale CDR less pressing. Although there are major political and cultural barriers to putting issues of population and consumption on the table there is no doubt they can be influenced significantly by policy levers, especially when looking forward over many decades. And discussion of these sorts of options will form part of the political context within which choices about CDR will ultimately be made.

Coming to grips with climate change is about learning to negotiate environmental limits. If global trends continue, these limits will be increasing evident in problems such as the provision of fresh water, the health of the oceans, the loss of biodiversity, disruption of the nitrogen cycle, constraints on food supply and chemical loadings (MEA 2006; Rockström et al. 2009). Although climate change can be approached as a technical issue of managing positive and negative emissions and the radiative balance of the atmosphere, it can be seen more broadly as the result of a collision between the established societal development path and the material limits of the biosphere. Twenty-five years ago the World Commission on Environment and Development suggested the concept of 'sustainable development' to capture the idea of a modified development trajectory which could satisfy human aspirations for a better life without tipping the planet towards ecological disaster (WCED 1987). Although in political argument 'sustainable development' has been subject to countless interpretations and much misuse (sharing the fate of other normative concepts such as 'democracy', 'freedom' or 'justice), it has the virtue of highlighting two major realities (Lafferty 1996). First, that in the modern world environmental issues such as climate change cannot be understood or managed successfully without addressing the development pressures which lie at their source. And this implies movement away from a pattern of economic 
activity based on crude material growth (the endless expansion in the numbers of people, in the absolute consumption of renewable and non-renewable resources, and in the generation of wastes) (OECD 2011). Second, that the problems of the rich and the poor countries are entangled: so attempts to address climate change ultimately will require some accommodation of the perspectives of each.

The societal response to human induced climate change will unfold over many decades, and we can anticipate false starts and reverses, alternating periods of innovation and stagnation, and dramatic reversals of direction in light of new knowledge and continuing experience. This essay has argued that in coming years the CDR-related policy challenge is to develop a nuanced approach, which differentiates among options and the specific ways they are to be governed, and which trials them at modest scale to allow learning from experience, the operation of social feed-back mechanisms, and the careful adjustment of regulatory frameworks. While some CDR approaches may offer useful additions to the mitigation 'tool kit', issues of cost, environmental risk, physical limits and tension with other societal practices mean they can represent only part of any solution. Above all, they do not alter the basic fact (and the most urgent climate-related policy challenge), that human societies need to curtail releases of greenhouse gasses associated with fossil fuel usage as quickly as possible.

Acknowledgement The author acknowledges the support of the Canada Research Chairs program.

Open Access This article is distributed under the terms of the Creative Commons Attribution License which permits any use, distribution, and reproduction in any medium, provided the original author(s) and the source are credited.

\section{References}

Azar $\mathrm{C}$ et al (2010) The feasibility of low $\mathrm{CO}_{2}$ concentration targets and the role of bio energy with carbon capture and storage (BECCS). Climactic Chang 100:195-202

Baccini A et al (2012) Estimated carbon dioxide emissions from tropical deforestation improved by carbondensity maps. Nat Clim Change 2:182-185

Bennett C, Howlett M (1992) The lessons of learning: reconciling theories of policy learning and policy change. Pol Sci 25:275-292

Bipartisan Policy Center (2011) Report of the task force on climate remediation research

Creutzig F et al (2012) Reconciling top-down and bottom-up modeling on future bioenergy deployment. Nat Clim Change 2:320-327

Dosi G (1982) Technological paradigms and technological trajectories: a suggested interpretation of the determinants and directions of technical change. Res Policy 11:147-162

Freeman C (1996) The greening of technology and models of innovation. Technol Forecast Soc Chang 53 (1):27-39

Geels F (2005) Technological Transitions and System Innovations: A Co-evolutionary and Socio-technical Analysis, Edward Elgar

Geels F, Schot J (2007) Typology of sociotechnical transition pathways. Res Policy 36:399-417

Harris $\mathrm{N}$ et al (2012) Baseline map of carbon emissions from deforestation in tropical regions. Science 336 (6088):1573-1576

Horton J (2011) Geoengineering and the Myth of Unilateralism. Stanf J Law Sci Pol 4:56-69

IEA (2012) World Energy Outlook 2012, International Energy Agency

Keith D (2000) Geoengineering the climate: history and prospect. Ann Rev Energy Env 25:245-284

Keith D, Ha-Duong M, Stolaroff J (2006) Climate strategy with $\mathrm{CO}_{2}$ capture from air. Climactic Chang $74: 17-45$

Kingdon J (1984) Agendas, alternatives and public policies, Little, Brown and Company

Kohler P, Hartmann J, Wolf-Gladrow D (2010) Geoengineering potential of artificially enhanced silicate weathering of olivine. Proc Natl Acad Sci 107(47):20228-20233 
Lackner K (2009) Capture of carbon dioxide from ambient air. Eur Phys J Spec Top 176:93-106

Lafferty W (1996) The politics of sustainable development: global norms for national implementation. Environ Polit 5:185-208

Lenton $\mathrm{T}$ (2010) The potential for land-based biological $\mathrm{CO}_{2}$ removal to lower future atmospheric $\mathrm{CO}_{2}$ concentration. Carbon Manag 1:145-160

Lenton T, Vaughan N (2009) The radiative forcing potential of different climate geoengineering options. Atmos Che Phys Discuss 9:2559-2608

Lindblom C (1979) Still muddling, not yet through. Publ Admin Rev 39:517-526

Lovley D, Chapelle F (1995) Deep subsurface microbial processes. Rev Geophys 33:365-381

MEA (2006) Ecosystems and Human Well-Being: Synthesis Report, Millennium Ecosystem Assessment, Earthscan Meadowcroft J (2007) Who is in charge here? Governance for sustainable development in a complex world. J Environ Pol Plan 9:299-314

OECD (2011) Towards green growth. Organization for Economic Co-operation and Development, Paris

Pan Y et al (2011) A large and persistent carbon sink in the world's forests. Science 333(6045):988-993

Ranjan, Herzog (2011) Feasibility of air capture. Energy Procedia 4:2869-2876

Rockström J, Steffen J, Noone K, Persson A, Chapin F III, Lambin E, Lenton T et al (2009) A safe operating space for humanity. Nature 461:472-475

Royal Society (2009) Geoengineering the Climate. The Royal Society, London

Sanden B (2004) Technology path assessment for sustainable technology development. Innov: Manag Pol Pract 6:316-330

Schellnhuber H (2006) Avoiding dangerous climate change, Cambridge University Press.

Smith A, Voß J, Grin J (2010) Innovation studies and sustainability transitions: the allure of the Multi-Level Perspective and its challenges. Res Policy 39:435-448

Socolow R et al (2011) Direct air capture of $\mathrm{CO}_{2}$ with chemicals. APS Phys 1:1-119

Torvanger A, Meadowcroft J (2011) The political economy of technology support: making decisions about CCS and low carbon emission energy technologies. Glob Environ Chang 21:303-312

Unruh G (2000) Understanding carbon lock-in. Energy Pol 28:817-830

Vergragt P, Markusson N, Karlsson H (2011) Carbon capture and storage, bio-energy with carbon capture and storage, and the escape from the fossil fuel lock in. Glob Environ Chang 21:282-292

Virgoe J (2009) International governance of a possible geoengineering intervention to combat climate change. Clim Chang 95:103-119

WCED (1987) Our common future, World Commission on Environment and Development, Oxford University Press 